Prospective teachers' views toward the use of English as the medium of instruction in early childhood classes in the United Arab Emirates

\author{
Ismail, Sadiq Abdulwahed Ahmed $\triangle$ \\ United Arab Emirates University, UAE (Iyad333@ hotmail.com) \\ Shaban, Mohamad Sadeg \\ United Arab Emirates University, UAE (MShaban@uaeu.ac.ae)
}

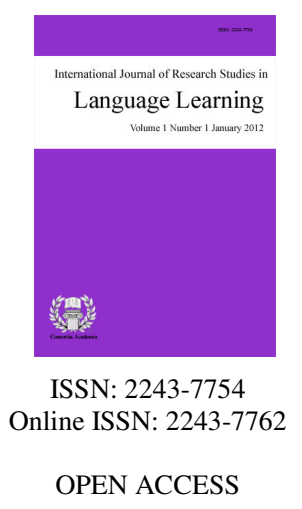

Received: 23 October 2015

Revised: 24 December 2015

Available Online: 21 February 2016

DOI: $10.5861 / \mathrm{ijrs} 11.2016 .1360$

Accepted: 2 February 2016

\begin{abstract}
The medium of instruction issue has continuously been discussed in relation to standards of education. It has been for a long time a controversial issue and sometimes a complicated one in many countries, including the United Arab Emirates (UAE). The main objective of this study was to investigate prospective teachers' views about the use of English as the medium of instruction in KG classes. Sixty-two students in the Early Childhood Program in the College of Education at the UAE University participated in the study and only 21 students volunteered to take part in the focus-group interviews. A questionnaire and a focus group interview were used as the two main tools for collecting data. The overall results demonstrate prospective teachers' positive views about English language and its use as the medium of instruction in children's classes. Major results highlight the importance of using English in KG classes for developing children's communication skills and assisting them to gain more confidence at subsequent stages of their education. Another important result demonstrates the role of English in helping children to develop intellectually, socially and linguistically. In order to guide future research in this area, recommendations were discussed and recorded toward the end of the article.
\end{abstract}

Keywords: English language; instruction; medium; perceptions; early childhood 


\section{Prospective teachers' views toward the use of English as the medium of instruction in early childhood classes in the United Arab Emirates}

\section{Introduction}

The issue of using English language as the medium of instruction in schools has been investigated by a number of researchers (Berriz, 2006; Spanos, 2006; Graddol, 2005; Wright, 2004; Biggs, 1990; Uys, Walt, Berg, \& Botha, 2007; Troudi, 2007; Man-Ling, 2004; Marsh, Hau, \& Kong, 2000). Those researchers and others highlighted the positive and negative impact of the use of English in teaching on educational learning outcomes. Many parents today in different countries including the United Arab Emirates (UAE) are interested in sending their children to schools where English is the medium of instruction. English is seen as the language of opportunities for flourishing jobs and a better future life (Hengsadeekul, Koul, \& Kaewkuekool, 2014; Qian, 2008). However, some research reported results not in favor of using English in teaching content area subjects such as math and science (Basibek, Dolmaci, Cengiz, Bur, Dilek, \& Kara, 2014; Tarhan, 2003). English in the UAE today is gaining more importance as it was recently introduced as the medium of instruction for science and math in elementary schools in the emirate of Abu-Dhabi and a few selected schools in other emirates. Research has highlighted the needs to conduct a thorough review of the UAE's educational system (Gaad, Arif, \& Scott, 2003).

The issue of using English as the medium of instruction has not only been raised and discussed in countries where English is a second and/or foreign language but it is also raised by educators in contexts where English is the first language such as the United States. Christian (2007) discussed in a report that many new comer students joining the educational system in the United States every year need special programs to help them improve their language skills and understand the curriculum content in subjects such as science and math which are vital for future life success. Academic success of students in this case depends on the adaptation of an approach that focuses on both language and curriculum content. The application of such approach depends very much on the teachers' qualification, experience and educational background. Since learning the language is vital for accessing the curriculum, subject matter teachers who are using English as a sole medium of instruction should be certified in both ESL and their subject matter specialization.

In an attempt to advance education in the UAE and to make more departure from rote learning, the UAE introduces two approaches to school curriculum. A new standards-based curriculum was introduced in Abu Dhabi schools and a new English-medium curriculum was implemented in selected government schools in other emirates. In both approaches English is used as the language of delivering contents of some subjects such as science and math. The present study investigated an issue related to these approaches to find out about the views and readiness of future teachers to adopt and work within the new curriculum approaches. Thus, this study investigated how future teachers views the use of English in teaching small children and the impact of such practice on children's education in general and learning outcomes in particular.

\section{Literature Review}

There has been a lot of controversial discussion about the widespread of English as a medium of instruction in schools and tertiary education. The adoption of English as a medium of instruction may result in positive or negative educational outcomes (Graddol, 2005; Wright, 2004; Biggs, 1990; Uys, Walt, Berg, \& Botha, 2007; Altinyelken, Moorcroft, \& van der Draai, 2014; Man-Ling, 2004; Marsh, Hau, \& Kong, 2000). The need to be proficient in the use of a second language (English) among children whose first language is not English has become an issue in many countries worldwide, including the UAE. Recently, educators in different parts of the globe have faced a challenge of addressing the needs of the growing number of children whose primary language is not English (Poole, 2013; Evans, \& Morrison 2011; Gibbons, 2003; Yu, 2015). While mastering other skills 
and content in other subject areas, those students are required to develop high proficiency in English (Vizconde, 2006). Developing such language proficiency requires teachers to modify their instruction to the students' level and to integrate content and language instruction. This approach may have more benefits if the subject matter teachers have experience and/or qualification in teaching English as a second/foreign language. Christian (2007) highlighted the conditions of success for any program serving students whose first language is not English. Programs serving English language students should mainly target language proficiency improvement and high standards in grasping the curriculum content.

Even in the United States of America (USA) where there are many people flooding into the country every year, studies show that this issue of using the target language as the medium of instruction is still very difficult (Berriz, 2006; Spanos, 2006; Reyhner \& Davison, 1992). This challenge still exists in the USA's public schools in spite of the fact that both teachers and educators have been developing and maintaining suitable instruction for students learning English as a second language for decades. Blake and Sickle (2001) identified one of those strategies as code-switching from the informal local dialect to a more formal instruction, which found to be better as students achieved better in some content area subjects. This approach might not be applicable in other areas where code-switching was not used, but other procedures, such as immersion or sheltered programs might be appropriate for improving learners' language proficiency and academic achievements (Zin, Wong, \& Rafik-Galea, 2014; Rossell, 2005).

Within the context of Hong Kong, a number of researchers investigated the impact and current situation of English as the medium of instruction (Wendy, 2004; Li, Leung \& Kember, 2001; Evans \& Morrison, 2011; Evans, 2002, 2000; Lin \& Morrison, 2010). Evan (2000), for example, reported that people who favor the use of English as the Medium of instruction in schools are parents and business people. Parents feel that the use of the second language as the language of instruction in schools may offer students with very valuable opportunities to learn and achieve high language proficiency in English. Similarly, the business community believes that high levels of proficiency in the language are essential for maintaining Hong Kong's status as a leading industrial, commercial and financial center. Wendy (2004) examined the effectiveness of the current single medium of instruction policy in two secondary schools in Hong Kong. The study was conducted to examine the views and instructional practices of a number of teachers in two schools in Hong Kong. The results demonstrated that teachers in both schools did not exactly follow the single medium of instruction policy. The teachers were found to use a mixed code as part of their everyday teaching as they believe that this practice might assist in maximizing students' learning. It was concluded that the mixed code teaching can serve a number of valuable pedagogic functions as teachers reiterated that this practice may help facilitate teaching and learning in different classes.

In another context, Kyeyune (2003) raises the issue of the importance of using English as the medium of instruction to advance education and learners' achievement. It is stated that there is a great public concern in Africa, including Uganda that the poor English proficiency of students and teachers will result in low standard education and poor achievements. Kyeyune (2003) interviewed some teachers and students and reported some of the ways in which teachers tried to follow when using English as a medium of instruction in their classes. It was reported that the use of English as the medium of instruction sometimes obstructs learners' endeavors to perform better instead of assisting in facilitating those efforts to improve their learning.

In a study about "parents and teachers' perceptions of mother-tongue medium of instruction policy in Nigerian primary schools", Iyamu and Ogiegbaen (2007) reported that both parents and teachers appreciated the advantages of mother-tongue education, but parents were reluctant to let their children follow their education in the first language. They reported two major obstacles that hinder the use of the first language as the medium of instruction. The first problem is that there is a great demand from the public for a language of wider communication and interaction. The second obstacle represented by the lack of suitable teaching materials to be used along with the first language. It was indicated that there is a belief in the Nigerian society that learning in the mother tongue is inferior to learning in English. Teachers are also reluctant to shift to the first language as the 
medium of instruction as they fear to lose status among their colleagues. They ended their study with a suggestion to reorient parents in particular and the public in general on the place of the mother-tongue in education. However, in the UAE today many parents want their children to join English medium schools not because they underestimate the role of first language instruction but because they believe that there is a growing needs in the job markets for graduates who possess a high command of English language. English is seen as the language that may help in establishing a successful academic, professional and social future life (Shaban \& Ismail, 2013; Gaad, Arif, \& Scott, 2006).

In another study within the Nigerian context, Egwuogu (2011) investigated teachers' perceptions of the continued use of English as the language of instruction in Nigerian schools. The results indicated that teachers believe that English is not responsible for the fallen standard of education and, therefore, it should continue to be used as the language of instruction in Nigerian schools. All learners following their education in English as a sole medium of instruction are facing the same dual challenges: improving English language proficiency and acquiring knowledge and academic skills in disciplines such as math and science which are considered essential for better future life. In such situations, instruction should always be reviewed and adjusted to cater for learners' immediate and future needs.

Within the Malaysian context Hudson (2009) dealt with perspective teachers who were learning to teach science using English as the sole medium of instruction. An open ended questionnaire was used to collect data about perspective teachers' perceptions regarding their preparation to teach science using English as the medium of instruction. Teachers were found to be positive about their preparation and they considered English vocabulary, pronunciation and grammar essential for developing conceptual knowledge in science education. Participants acknowledged the needs to teach science in English as it is taught in that language in higher education programs.

In other studies, students reported positive attitudes towards the use of English as the medium of instruction in their classes. In a study about students' attitudes towards English, for example, Mamun, Rahman, Rahman, and Hossain (2012) found that the respondents were positive towards English language and they attributed this result to the fact that the respondents might be instrumentally motivated to follow their study in English. They indicated that they like both the language and the people who speak that language. Students in this study showed that they are aware of the importance of English in this era of globalization and global communication network. The results also highlighted students' beliefs regarding the opportunities that the knowledge of English might offer when seeking a good job and securing a better social position.

Within the same line Wong (2010) investigated The Effectiveness of Using English as the Medium of Instruction in English Classes. A class where the first language (Cantonese) was allowed was compared with another class where English was only used for instruction. It was found that the class where English was strictly used developed positive attitudes toward the target language and they indicated their strong preferences to be taught through English only. Students in the strictly-English policy class also developed higher language proficiency than the other class where students' first language was permitted.

In a doctorate dissertation, Tarhan (2003) looked at the perceptions of students, teachers and parents regarding the implementation of English as the medium instruction and their perceptions of English as a foreign language. A questionnaire and a semi-structured interview technique were used as the two major instruments for data collection from all participants. The study reported results against the use of the target language in teaching content area subjects. All groups participated in the study, students, teachers and parents, expressed their opposition toward the use of English-medium instruction in secondary education programs. Without any exceptions, all groups highlighted certain obstacles and/or problems that may hinder the implementation of English as the medium of instruction at Anatolian high schools. It was found that there is a positive correlation between perceptions of English and perceptions of English as the medium of instruction for each group. Other important results also demonstrated that all groups possess a positive view toward English as a foreign language and they are in favor of the idea of teaching and learning English as a foreign and/or second language. Teachers 
Prospective teachers' views toward English as the medium of instruction in UAE early childhood classes

and students perceived that problems may arise as a result of using English as the medium of instruction. It was concluded that the use of English as the medium of instruction may pose problems in the learning of the subject matters, such as science and math in Anatolian high schools.

Similarly, Chan, and Tan (2006) raised certain possible barriers that may impact the use of English as the sole medium of instruction for math and science. In their study, they discussed controversial issues that may affect the use of English for teaching math and science in Malaysia such as difficulty of mastering English, disadvantages of bilingual learning, the rural-urban learners' capability, the national identity, and many others.

\subsection{Research Questions}

The purpose of this study is to investigate early childhood prospective teachers' beliefs toward the use of English as the medium of instruction in KG classes in the United Arab Emirates. It will seek to answer the following three Questions:

$>\quad$ How do prospective teachers perceive the use of English as the medium of instruction in KG classes?

$>\quad$ What are the advantages of using English as the medium of instruction in KG classes?

$>\quad$ What are the shortcomings of using English as the medium of instruction in KG classes?

\section{Methodology}

\subsection{Participants}

The population of this study included all the students enrolled in the Early Childhood Education Program in the College of Education at the United Arab Emirates University (UAEU) (166 female students). Only sixty two senior students participated in this study by completing and returning the questionnaire. Only 21 students volunteered to take part in the focus group interviews. All participants were female students enrolled in the Early Childhood Education Program and they are hoping to become teachers in KG schools after finishing their bachelor of education degree. Students agreed to participate in the study after they were informed about the purpose and confidentiality of the study. English language is used as the medium of instruction for almost all courses in their discipline in the College of Education. Most of those students have already spent at least two years in the College of Education. Their English language proficiency is determined by their scores in the IELTS Exam. Most of their scores fall within the score bands of 4.5 and 5.

\subsection{Research Instruments}

This study adopted both quantitative and qualitative approaches for data collection. A questionnaire was employed to gather quantitative data from all participants while focus group interviews were conducted with only some participants volunteering to take part in the interview.

Questionnaire - A five point Likert-scale questionnaire was developed by the researchers to collect the required data to answer the three research questions. All 22 items of the questionnaire were initially drafted in the light of the objectives and/or the three research questions of the study. Later, only 22 items were categorized and put into three main themes to match the purposes of the study and/or the three research questions. All other items were dropped out at this stage. In order to establish its validity, the questionnaire was given to a panel of six university faculty members who are experienced and experts in conducting research in the field of education. After receiving the reviewed draft of the questionnaire from the evaluators, the researchers discussed some of the points with them and reached an agreement of the nature of the final draft of items. Later, the two researchers rigorously reviewed and redrafted the questionnaire in accordance with the reviewers' comments and feedback. The reliability of the questionnaire was also checked and established using the Cronbach-alpha. Its value was 
Ismail, S. A. A., \& Shaban, M. S.

found to be .91 which is considered an acceptable measure for such instrument.

Focus Group Interviews - The four focus group interviews' questions were developed to gather qualitative supportive data for the quantitative data collected by the questionnaire. The four questions were drafted by the researchers based on the themes and issues that the questionnaire sought to explore. Similarly, all these questions were given to the same evaluators who looked at the questionnaire. Reviewers were requested to examine if the questions might serve the purpose of the study and help in generating supportive data for the data collected via the questionnaire. Finally, these questions were reviewed and redrafted in the light of the evaluators' comments and/or suggestions. Only twenty one students participated in the focus group interviews. At a subsequent stage, the data collected via the focus group interviews was only used in the discussion to support the quantitative data collected by using the questionnaire.

\subsection{Data Collection}

A research assistant was recruited and trained to help in collecting, managing and keeping the data. A number of students from both the Early Childhood program and the English program also volunteered to distribute and collect the questionnaire on campus and in the dormitories. After collecting the quantitative data during the academic year of 2012-2013, the researchers met with the research assistant several times to offer training and explanation for conducting the focus group interviews. All measures were taken in order to ensure that the research assistant has understood how to conduct the interviews properly. The two researchers conducted two focus group interviews each and the research assistant conducted only one interview after participating in one of the interviews carried out by one of the researchers. Since some participants chose not to be video-taped and/or recorded during the focus group interviews, the researchers and the assistant researcher recorded the data manually.

\subsection{Data Analysis}

The data collected via the questionnaire was analyzed using the SPSS program to obtain descriptive statistics. Means, standard deviations and rank were obtained to determine the most and least frequent results for each item and/or theme. The overall mean scores and standard deviations were also calculated. Following a qualitative analysis technique suggested by Patton (2002), the researcher looked at "the details and specifics" of the data collected via the focus group interviews. The data was organized, categorized into themes and represented in tables and/or charts to make it more visible. Initially, the data was categorized and put into themes and later the frequency of each theme and/or item was counted and recorded in order to trace recurrent patterns.

\section{Results and Discussion}

Table 1 demonstrates the results of question one about prospective teachers' perceptions of the use of English as the medium of instruction in KG classes. The mean scores of all items ranged from 4.30 to 3.67. The first highest result $(\mathrm{M}=4.30 \& \mathrm{SD}=0.98)$ highlighted the importance of using English as the medium of instruction in improving children's communication skills. This high result might be attributed to the students' own knowledge and experience about acquiring the first and second language. Students might also have looked at their own personal experience in learning English at different levels in schools. This result is similar to findings reported by other researchers regarding the positive attitudes of students toward English (Mamun, Rahman, Rahman, \& Hossain, 2012; Wong, 2010; Hudson; 2009). Students' comments during the focus group interviews support the positive result above. They stressed the importance of using English in instruction in order to assist children in developing high language proficiency in English. A student stated: "I think children will learn better if English is used to teach science and math because children can learn language very easily in early ages and through math and science they can learn new concepts in easy ways." The discussions during the focus group interview reflect that prospective teachers are fully aware of children's future needs for English. The following is an example excerpt of what one of them said: "When they learn math and science in English it will 
Prospective teachers' views toward English as the medium of instruction in UAE early childhood classes

be easy for them in the future to understand math and science." Another participant stressed the same issue in her own words: "Yes it's better for children to learn English because in future all their study will be in English. In the university nowadays, we study everything in English". Prospective teachers' enthusiasm for the use of English as a sole medium of instruction in KG classes may be attributed to their experience in their program of study at the university. Almost all courses in the Early Childhood Teacher Preparation Program at the College of Education in the UAE University are delivered in English. Any successful program involved ESL learners should continuously keep an eye on facilitating learners' comprehension and developing better language proficiency levels.

The second and third highest results highlighted the role of English as the medium of instruction in providing students with valuable opportunities to have continuous contact with the language and to learn how to use technology efficiently. These results demonstrate that those students are aware that knowledge of English is essential for communication and for learning how to use technology efficiently. In a study about the language of instruction dilemma in the Turkish context, Sert (2008) reported that English medium approach was found to be the most effective of all other approaches. The lowest result $(\mathrm{M}=3.7 \& \mathrm{SD}=1.150)$ highlighted students' views regarding the role of the language in motivating students to study harder. Some students referred to the impact of using English continuously in instruction on children's motivation and readiness to use the language. This extract from the focus group interviews is an example of how students view motivation for using English: "teaching science or any subject in English will increase motivation to talk to foreigners and read English stories. I think they will be excited when they speak English."

\section{Table 1}

Prospective teachers' perceptions of the use of English as the medium of instruction in KG classes

\begin{tabular}{lccc}
\hline \multicolumn{1}{c}{ Using English as the medium of instruction will: } & Mean & SD & Rank \\
\hline 1. help children at early ages learn two languages and become bilingual. & 4.05 & 1.05 & 6 \\
2. help children develop positive attitudes toward foreign languages. & 4.11 & 0.92 & 5 \\
3. help children learn the language very quickly. & 3.98 & 0.99 & 7 \\
4. improve students' language competence. & 4.18 & 0.82 & 4 \\
5. provide students with valuable opportunities to continuously use the language. & 4.21 & 0.83 & 3 \\
6. assist children in improving their communication skills. & 4.30 & 0.98 & 1 \\
7. help children learn how to use technology. & 4.21 & 1.03 & 2 \\
8. motivate students to study harder. & 3.67 & 1.15 & 9 \\
9. enable children to learn about the culture of the target language. & 3.97 & 0.97 & 8 \\
Overall & 4.07 & 0.97 & \\
\hline
\end{tabular}

Table 2 reveals the results of questions 2 regarding the advantages of using English as the medium of instruction in KG classes. The overall mean score for this category is just above 4 (4.0787). This high result indicates that students are aware of the advantages that English language might have for small children when it is used as the medium of instruction. The mean scores of all items in this category ranged from 4.32 to 3.84 . The first highest result $(\mathrm{M}=4.32 \& \mathrm{SD}=.78)$ stresses the fact that knowledge of English is essential for elevating students' confidence and how that might help them in subsequent stages of their education. This result is in line with Wong's (2010) findings about the use of only English as the Medium of Instruction. In Wong's study, learners who were taught by English only were found to have positive attitudes toward the target language and they indicated a strong preference to be taught only in English. The second and third highest results show how knowledge of English may help in developing children's thinking skills and also in promoting precise knowledge of different concepts (see table 2). The fourth ranked highest result shows the students' views about the advantages of using English for teaching children in learning different sciences.

The least ranked result $(\mathrm{M}=3.84 \& \mathrm{SD}=1.04)$ highlights students' view regarding the impact that English might have on children's achievements in science and math. This result indicates that students are skeptical about the role of children's knowledge of English in improving their performance in both science and math. A considerable number of students did not agree that children's knowledge of English has the power to enhance 
their accomplishments in science and math. This result is similar to Egwuogu's (2011) findings about the falling standards of education. The results of Egwuogu revealed that English was not responsible for the falling standards in education and/or students' performance. Kyeyune (2003) reported that the use of English as the sole medium of instruction sometimes obstructs learners' attempts to perform better instead of assisting in facilitating those efforts to improve their learning. Other studies also reported similar results regarding the negative impact of using English as the medium of instruction for teaching subject matters (Tarhan, 2003). Students during the focus group interviews expressed their concern about the use of English for teaching math and science in KG classes as they thought that abstract concepts are very difficult to be learned even in the first language: "No, I think it's better if children learn math and science by using their native language. There are scientific vocabularies that the students' mind can't process and learn. It's difficult for native speakers to learn that, so absolutely children in KG will not benefit at all." However, other students thought that the successful delivering of the content in English depends on the selection of appropriate approaches: "Children learning depends on how the teacher delivers knowledge. But I believe both science and math should be taught in Arabic for KG classes because if they use English to teach science, children may not know the concepts in Arabic."

\section{Table 2}

Prospective teachers' perceptions of the advantages of using English as the medium of instruction in KG classes

\begin{tabular}{|c|c|c|c|}
\hline Using English as the medium of instruction: & Mean & SD & Rank \\
\hline $\begin{array}{l}\text { 10. will have a positive effect on students' achievements especially in science and } \\
\text { math subjects. }\end{array}$ & 3.84 & 1.04 & 7 \\
\hline 11. helps children gain social prestige. & 3.97 & 0.97 & 5 \\
\hline 12. will make children like school and education. & 3.95 & 1.16 & 6 \\
\hline 13. can promote better learning of different sciences. & 4.00 & 1.00 & 4 \\
\hline 14. will help children learn different concepts accurately. & 4.29 & 0.75 & 2 \\
\hline 15. will help children develop confidence in subsequent stages of their education. & 4.32 & 0.78 & 1 \\
\hline 16. will help children develop better thinking skills. & 4.19 & 0.98 & 3 \\
\hline Overall & 4.08 & 0.96 & \\
\hline
\end{tabular}

Table 3 highlights the results of research question 3 about the disadvantages of using English for teaching children in KG classes. Compared with the overall results of the previous two categories or questions, the overall mean score (3.11937) for this category is not very high. The mean scores of all items ranged between 3.29 and 2.83. The highest mean score (3.29) is viewed as very low when comparing it with results from the previous question about the advantages of using English. Many students $(M=3.29)$ do not believe that English may have a negative impact on children's knowledge of their first language productivity. The lowest ranked result reveals students' perceptions of the impact that English may have on children's relationships with other children in the community. This result highlights students' beliefs about the positive role that English may play in assisting children to develop relationships with other children in the community. Supportive evidence for this result is found in the students' comments during the focus group interview sessions: "Yes, because children can communicate with other people in other countries and they can use technology in easy ways, and they will also gain new experience and skills." Another student also continued to say: "Yes, it will help them because they will study all courses in the university and colleges in English. If they want to communicate with anybody, they should learn English because many people speak only English. This will benefit them in their future work."

Almost all individual results of the six items in table 3 highlight students' positive attitudes and views about the use of English as the medium of instruction. Support for their answers of the questionnaire is found in their talk during the interviews: "children will be more able to speak correctly...oh...no I mean fluently in the future and that will help them finish courses in the university quickly with high grades or GPA". It is obvious that prospective teachers believe that the use of English in teaching children in KG classes is essential for offering better education and assist children to develop socially, mentally and linguistically. Wong's (2009) results support the findings of the present study. Wong, for example, reported that students who followed instruction in English developed positive attitudes towards the target language and they indicated preference for the use of English as the sole medium of instruction. In brief, perspective teachers in the present study seem to have no 
Prospective teachers' views toward English as the medium of instruction in UAE early childhood classes

serious concerns regarding the disadvantages of using English as the medium of instruction. In the focus group interviews some of them indicated that a good teacher can make the content very easy for students even if students' language proficiency is not very high, "Children's learning depends on how the teacher delivers knowledge. But I believe both science and math should be taught in Arabic for KG classes because if they use English to teach science, children may not know the concepts in Arabic." In this line Christian (2007) discussed some approaches that might be used to improve students' language proficiency and help them understand the content. Focusing on both language and content is a common practice in immersion programs as language is a key factor in academic success and it provides the passage for dealing with the curriculum. In the literature there is evidence in favor of the use of English as the medium of instruction. Tung, Lam \& Tsang (1997) reported that students and their parents are in favor of English medium instruction in Hong Kong though the country moved back from the British Throne to China. However, other studies reported advantages in favor of the first or local languages. In a study conducted within the Ugandan context, Altinyelken, Moorcroft, and van der Draai (2014), for example, reported results that emphasize the role of local languages in improving students' literacy skills, understand of contents and the average of their participation.

\section{Table 3}

Prospective teachers' perceptions of the shortcomings of using English as the medium of instruction in KG's classes

\begin{tabular}{|c|c|c|c|}
\hline Using English as the medium of instruction: & Mean & SD & Rank \\
\hline $\begin{array}{l}\text { 17. may promote a negative effect on students' attitudes toward their first } \\
\text { language. }\end{array}$ & 3.10 & 1.40 & 5 \\
\hline 18. will negatively affect children's first language competence. & 3.29 & 1.30 & 1 \\
\hline $\begin{array}{l}\text { 19. discourages the development and/or the production of newly Arabic learned } \\
\text { words. }\end{array}$ & 3.29 & 1.35 & 2 \\
\hline 20. does not help students learn scientific words in Arabic. & 3.13 & 1.53 & 3 \\
\hline 21. will negatively affect children's native culture. & 3.10 & 1.35 & 4 \\
\hline $\begin{array}{l}\text { 22. will negatively impact children's relationships with other children in the } \\
\text { community. }\end{array}$ & 2.83 & 1.43 & 6 \\
\hline Overall & 3.12 & 1.39 & \\
\hline
\end{tabular}

\subsection{Recommendations}

The results of this study emphasize prospective teachers' positive attitudes toward the target language use in teaching in $\mathrm{KG}$ classes and how children may be assisted in developing higher language skills and acquiring academic skills and knowledge in different disciplines such as science and math. Since language provides access to academic disciplines, it is very vital to ensure that instructors teaching other subjects have some training, knowledge and/or experience in integrating ESL into the objectives of the academic curriculum. Although this study has made significant contributions to language instruction in children's classes, more studies are still needed to investigate this issue in more depth and from different perspectives. Studies might be conducted to examine the kind of difficulties children are facing when English language is used as the medium of instruction. Another study, for example, might try to investigate the effectiveness of different approaches used for teaching $\mathrm{KG}$ classes and their impact of children's achievements.

\section{Conclusion}

This study examined the views of prospective teachers' perceptions regarding the use of English as the medium of instruction in KG classes. It also highlighted the advantages and shortcomings of such practice from the point of views of students. A combination of quantitative and qualitative methods was employed for conducting this research. The overall results clearly demonstrate students' positive views toward English language and its use as the medium of instruction in children classes in UAE's schools. Students believe that English may play crucial role in children's early and subsequent education. An important result highlighted the 
crucial role of English in promoting children's communication skills. Another important result revealed the role that English may play in developing children's confidence and assisting them in subsequent stages of their education. Overall, prospective teachers believe that the use of English as the medium of instruction in KG classes will help children develop mentally, socially and above all linguistically.

Acknowledgement: This research project was funded by the Research Affairs at the UAE University under the contract no. 21D013-05/01/3150/12 with the first author. The researchers would like to thank the Research Affairs at the UAEU for funding this research project.

\section{References}

Altinyelken, H. K., Moorcroft, S., \& van der Draai, H. (2014). The dilemmas and complexities of implementing language-in-education policies: Perspectives from urban and rural contexts in Uganda. International Journal of Educational Development, 36, 90-99. http://dx.doi.org/10.1016/j.ijedudev.2013.11.001

Basibek, N., Dolmaci, M., Cengiz, B. C., Bur, B., Dilek, Y., \& Kara, B. (2014). Lecturers' perceptions of English medium instruction at engineering departments of higher education: A study on partial English medium instruction at some state universities in Turkey. Procedia-Social and Behavioral Sciences, 116, 1819-1825. http://dx.doi.org/10.1016/j.sbspro.2014.01.477

Berriz, B. (2006). Unz got your tongue: What have we lost with the English-only mandates? Radical Teacher, 75(1), 10-15.

Blake, M., \& Sickle, M. (2001). Helping linguistically diverse students share what they know. Journal of Adolescent and Adult Literacy, 44(5), 486-475.

Chan, S. H., \& Tan, H. (2006). English for mathematics and science: Current Malaysian language-in-education policies and practices. Language and Education, 20(4), 306-321. http://dx.doi.org/10.2167/le631.0

Christian, D. (2007). Programs for teaching English language learners. In A. Rosebery \& B. Warren (Eds), Teaching science to English language learners (pp. 131-147). Washington, D.C.: National Science Foundation.

Egwuogu, C. B. (2011). Teachers' perception of the continued use of English as the language of instruction in Nigerian schools. Journal of the Nigeria English Studies Association (JNESA), 14(1), 29-43.

Evans, S., \& Morrison, B. (2011). Meeting the challenges of English-medium higher education: The first-year experience in Hong Kong. English for Specific Purposes, 30(3), 198-208. http://dx.doi.org/10.1016/j.esp.2011.01.001

Evans, S. (2002). The medium of instruction in Hong Kong: Policy and practice in the new English and Chinese streams. Research Papers in Education, 17(1), 97-120. http://dx.doi.org/10.1080/02671520110084030

Evans, S. (2000). Classroom language use in Hong Kong's English-medium secondary schools. Educational Research Journal, 15(1), 19-43.

Gaad, E., Arif, M., \& Scott, F. (2006) Systems analysis of the UAE education system. International Journal of Educational Management, 20(4), 291-301. http://dx.doi.org/10.1108/09513540610665405

Gibbons, P. (2003). Mediating language learning: Teacher interactions with ESL students in content-based classroom, TESOL Quarterly, 37(2), 247-273. http://dx.doi.org/10.2307/3588504

Graddol, D. (2005). The future of English. The British Council: London.

Hengsadeekul, C., Koul, R., \& Kaewkuekool, S. (2014). Motivational orientation and preference for English-medium programs in Thailand. International Journal of Educational Research, 66, 35-44. http://dx.doi.org/10.1016/j.ijer.2014.02.001

Hudson, P. (2009). Learning to teach science using English as the medium of instruction. Eurasia Journal of Mathematics, Science, \& Technology Education, 5(2), 165-170.

Iyamu, E. O. S., \& Ogiegbaen, S.E.A. (2007). Parents and teachers' perceptions of mother-tongue medium of instruction policy in Nigerian primary schools. Language, Culture and Curriculum, 20(2), 97-108. http://dx.doi.org/10.2167/lcc328.0 
Prospective teachers' views toward English as the medium of instruction in UAE early childhood classes

Kyeyune, R. (2003). Challenges of using English as a medium of instruction in multilingual contexts: A view from Ugandan classrooms. Language, Culture and Curriculum, 16(2), 173-184. http://dx.doi.org/10.1080/07908310308666666

Li, N., Leung, D. Y. P., \& Kember, D. (2001). Medium of instruction in Hong Kong universities: The mismatch between espoused theory and theory in use. Higher Education Policy, 14(4), 293-312. http://dx.doi.org/10.1016/S0952-8733(01)00021-6

Lin, L. H. F., \& Morrison, B. (2010). The impact of the medium of instruction in Hong Kong secondary schools on tertiary students' vocabulary. Journal of English for Academic Purposes, 9, 255-266. http://dx.doi.org/10.1016/j.jeap.2010.09.002

Mamun, A., Rahman, M., Rahman, A., \& Hossain, H. (2012). Students' attitudes towards English: The case of life science school of Khulna university. International Review of Social Sciences and Humanities, 3(1), 200-209.

Man-Ling, M. (2004). Teachers' perceptions of using English as the medium of instruction in the subject of general studies in a Hong Kong primary school: A case study. Unpublished Master thesis, The University of Hong Kong.

Marsh, H., Hau, K. \& Kong C. (2000). Late immersion and language of instruction in Hong Kong high schools: Achievement growth in language and non-language subjects. Harvard Educational Review, 70(3), 303-345. http://dx.doi.org/10.17763/haer.70.3.gm047588386655k5

Qian, D. D. (2008). English language assessment in Hong Kong: A survey of practices, developments and issues. Language Testing, 25(1), 85-110. http://dx.doi.org/10.1177/0265532207083746

Patton, M. Q. (2002). Qualitative research and evaluation methods (3rd ed.). Thousand Oaks, CA: Sage Publications, Inc.

Poole, B. (2013). English-medium instruction at universities: Global challenges. System, 41(3), 880-882. http://dx.doi.org/10.1016/j.system.2013.07.004

Reyhner, J., \& Davison, D. (1992). Improving mathematics and science instruction for LEP middle and high school students through language activities. A paper presented as part of the Proceedings of the Third National Research symposium on Limited English Proficient Student Issues: Focus on Middle and High School Issues. Retrieved from http://www.ncela.gwu.edu/files/rcd/BE019308/Improving_Mathematics_and_Science.pdf

Rossell, C. (2005). Teaching English through English. Educational Leadership, 62(4), 32-36.

Sert, N. (2008). The language of instruction dilemma in the Turkish context. System, 36, 156-171. http://dx.doi.org/10.1016/j.system.2007.11.006

Shaban, M. S., \& Ismail, S. A. (2013). Exploring the nature of cooperation between teachers using English and those using Arabic as the medium of instruction in teaching KG classes in the United Arab Emirates. American International Journal of Contemporary Research, 3(8), 25-37.

Spanos, G. (2006). ESL math and science for high school students: Two case studies. Paper presented as part of the Proceedings of the Third National Research Symposium on Limited English Proficient Student Issues: Focus on Middle and High School Issues. Retrieved from http://www.ncela.gwu.edu/files/rcd/BE019304/ESL_Math_and_Science.pdf

Tarhan, S. (2003). Perceptions of students, teachers and parents regarding English- medium instruction at secondary education. Unpublished Doctorate Dissertation, The Graduate School of Social Sciences, Middle East Technical University.

Troudi, S. (2007). The effects of English as a medium of instruction. In A. Jendli, S. Troudi, \& C. Coombe (Eds.), The power of language: Perspectives from Arabia (pp. 3-19). Dubai: TESOL Arabia.

Tung, P., Lam, R., \& Tsang, W. (1997). English as a medium of instruction in post-1997 Hong Kong: What students, teachers, and parents think. Journal of pragmatics, 28, 441-459. http://dx.doi.org/10.1016/S0378-2166(97)00034-9

Uys, M., Walt, J., Berg, R., \& Botha, S. (2007). English medium of instruction: A situation analysis. South African Journal of Education, 27(1), 69-82.

Vizconde, C, J. (2006). Attitudes of Student Teachers towards the use of English as language of instruction for 
Ismail, S. A. A., \& Shaban, M. S.

science and mathematics in the Philippines. The Linguistics Journal, 1(3), 7-33.

Wendy, T. Y. N. (2004). An exploration of teachers' perceptions and instructional practices regarding the use and choice of language medium in two Hong Kong secondary schools. Unpublished Master Thesis, The University of Hong Kong.

Wolff, D. (2006). Content and language integrated learning. In K.-F. Knapp \& B. Seidelhofer (Eds), Handbook of Applied Linguistics. Springer: Berlin.

Wright, S. (2004). Language policy and language planning: From nationalism to globalisation. Palgrave Macmillan: London.

Wong, R. M. H. (2010). The effectiveness of using English as the sole medium of instruction in English classes: Student responses and improved English proficiency. Porta Linguarum, 13, 119-130.

Yu, B. B. (2015). Rethinking language education in Taiwan: A case of English majors' use of Chinese classifiers in translation. International Journal of Research Studies in Language Learning, 4(4), 57-68. http://dx.doi.org/10.5861/ijrsll.2015.970

Zin, Z. M., Wong, B. E., \& Rafik-Galea, S. (2014). Critical reading ability and its relation to 12 proficiency of Malaysian ESL learners. The Southeast Asian Journal of English Language Studies, 20(2), 43-54. http://dx.doi.org/10.17576/3L-2014-2002-04 